\title{
Review Paper: A Review on Brain Stimulation Using Low Intensity Focused Ultrasound
}

\author{
Ehsan Rezayat ${ }^{1 *}$, Iman Ghodrati Toostani ${ }^{2,3}$ \\ 1. Ultrasound Brain Stimulation Lab, Institute for Cognitive Science Studies, Tehran, Iran. \\ 2. Interunidades Bioengenharia (EESC/FMRP/IOSC), Neurocognitive Engineering Lab, Universidade de São Paulo, São Carlos, SP, Brazil. \\ 3. Research FGS (Fanavaran Gostaresh Salamat), Research and Development Department, Tehran, Iran.
}

Citation: Rezayat, E., \& Ghodrati Toostani, I. (2016). A review on brain stimulation using low intensity focused ultrasound. Basic and Clinical Neuroscience, 7(3), 187-194. http://dx.doi.org/10.15412/J.BCN.03070303

: http://dx.doi.org/10.15412/J.BCN.03070303

Article info:

Received: 08 July 2015

First Revision: 29 July 2015

Accepted: 03 January 2016

Key Words:

Low-intensity pulsed ultrasound (LIPUS), Non invasive brain stimulation (NIBS), Neuromodulation, Neuroimaging

\begin{abstract}
A B S T R A C T
Brain stimulation techniques are important in both basic and clinical studies. Majority of well-known brain stimulating techniques have low spatial resolution or entail invasive processes. Low intensity focused ultrasound (LIFU) seems to be a proper candidate for dealing with such deficiencies. This review recapitulates studies which explored the effects of LIFU on brain structures and its function, in both research and clinical areas.

Although the mechanism of LIFU action is still unclear, its different effects from molecular level up to behavioral level can be explored in animal and human brain. It can also be coupled with brain imaging assessments in future research.
\end{abstract}

\section{Introduction}

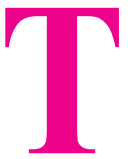

oday, brain stimulation techniques are used widely in research and clinical practices, like rewiring damaged brain circuits, modifying biological mechanisms of diseases, and treating neurological or psychological disorders. The majority of well-known brain stimulation techniques have low spatial resolution or entail invasive processes. Recent findings offer low intensity focused ultrasound (LIFU) as an amenity to deal with these deficiencies.

Sound is a mechanical wave, in the form of molecular vibrations, which transfers energy from one position to another. Ultrasound is a term used for the sound waves, which are propagated higher than audible range of human hearing. Ultrasound has been extensively used in medicine and industry since World War II. Ultrasound imaging, Doppler imaging, lithotripsy, sonophoresis, gene therapy, bone healing, drug delivery, peripheral nerve blocking, and tissue ablation are common applications of ultrasound in medicine. In the brain, ultrasound is used to open the blood brain barriers for drug administration. Furthermore, tissue ablation is done with exact precision using high intensity focused ultrasound (HIFU) (oskins, Martin, \& Thrush, 2010; Jolesz \& Hynynen, 2013; O’Brien, 2007; ter Haar, 2007).

Recently, MRI imaging is used to guide HIFU through tissues. Particularly in clinical brain studies, it is used to study Parkinson disease (Bauer et al., 2014), tremor (Lips-

* Corresponding Author:

Ehsan Rezayat, PhD Candidate

Address: Institute for Cognitive Science Studies, Pazhouheshkadeh Blv., Safir Omid Blv., Pardis New City (15 KMs North East of Tehran), Theran, Iran. Tel: +98 (21) 76291130

E-mail:erezayat.er@gmail.com 
man et al., 2013), and neuropathic pain in Zurich Hospital and some other centers (Bauer et al., 2014). In the same way, researchers want to use focused ultrasound in low intensities for brain stimulation instead of burning and ablation (Bystritsky et al., 2011).

\section{Overview of Low Intensity Focused Ultra- sound}

Present review explains benefits and risks of LIFU brain stimulation by exploring the following questions:

- Why should novel techniques be used in brain stimulation?

- Can LIFU stimulation change brain function?

- How does LIFU stimulation modulate neuronal functions?

- Can LIFU stimulation change corticospinal, thalamocortical, and corticocortical pathways?

- When will LIFU's safety be approved for clinical human brain stimulation?

2.1. Why should novel techniques be used in brain stimulation?

Brain stimulation has a localized and direct effect on neural circuits with fewer injuries in patients compared to pharmacological techniques. Stimulation of the neurons can be done by several means such as electrical, magnetic, optical, and mechanical. Table 1 categorizes some of the brain stimulation techniques that are used clinically or on the edge of research.
The most common neurostimulation techniques in clinical applications are deep brain stimulation (DBS), transcranial current stimulation (tCS), and transcranial magnetic stimulation (TMS). The goal is to achieve therapeutic utility and clinical efficacy for neurological and psychological disorders in spite of limitations of these methods. The pros and cons of the aforementioned techniques together with ultrasound as a new approach are presented in Table 2.

DBS is accompanied with intrusive operations, which may increase hazardous risks such as infection, limited longevity of electrical components, neural immune system reactions to external materials, and requirement of frequent battery replacement (Bronstein et al., 2011). In addition, DBS is not a safe procedure when coupled with fMRI (Zrinzo et al., 2011).

Both TMS and tCS fail to provide the spatial resolution required to target brain region of interests (ROIs). They are also unable to stimulate deeper ROIs without stimulating surrounding tissues (Parasuraman, Christensen, \& Grafton, 2012). However, recent generation of TMS machines use H-coil, which can focus more precisely than the conventional coils (Muggleton \& Walsh, 2012). Furthermore, the simultaneous use of rTMS/fMRI for brain mapping imposes various known difficulties (Ulmer \& Jansen, 2013; Peterchev et al., 2012). Optogenetics as a new approach may compete ultrasound in anatomic targeting despite its surgery requirements and gene expression (Diester et al., 2011; Fenno \& Deisseroth, 2014).

Neuroscientists try to make brain stimulation technologies noninvasive, inexpensive, user-friendly, direct, and safe. They believe that LIFU, regarding its features, can have a

Table 1. Some of brain-stimulation techniques used at the clinical and research level.

\begin{tabular}{|c|c|c|c|}
\hline Physical Basic & Technique & Abbreviation & Status \\
\hline \multirow{8}{*}{ Electrical } & Vagus nerve stimulation & VNS & Clinical \\
\hline & Deep brain stimulation & DBS & Clinical \\
\hline & Transcranial current stimulation & $\mathrm{tCS}$ & Clinical \\
\hline & Implanted electrocortical stimulation & IES & Research \\
\hline & Epidural cortical stimulation & ECS & Research \\
\hline & Trigeminal nerve stimulation & TNS & Research \\
\hline & Electroconvulsive therapy & ECT & Clinical \\
\hline & Cranial electrotherapy stimulation & CES & Clinical \\
\hline \multirow{2}{*}{ Magnetic } & Transcranial magnetic stimulation & TMS & Clinical \\
\hline & Repetitive TMS & rTMS & Clinical \\
\hline Optical & Optogenetics & - & Research \\
\hline
\end{tabular}


Table 2. Advantages vs. disadvantages of common brain stimulation techniques (adapted from Bystritsky et al., 2011).

\begin{tabular}{|c|c|c|c|c|}
\hline $\begin{array}{l}\text { Parameter } \\
\text { specify }\end{array}$ & $\begin{array}{c}\text { Deep brain stimula- } \\
\text { tion (DBS) }\end{array}$ & $\begin{array}{l}\text { Transcranial current } \\
\text { stimulation (tCS) }\end{array}$ & $\begin{array}{c}\text { Transcranial magnetic } \\
\text { stimulation (TMS) }\end{array}$ & $\begin{array}{c}\text { Low intensity focused } \\
\text { ultrasound stimula- } \\
\text { tion (LIFU) }\end{array}$ \\
\hline Invasiveness & Invasive & Noninvasive & Noninvasive & Noninvasive \\
\hline Spatial resolution & $\sim 1 \mathrm{~mm}$ & Undetectable & $\sim 3-5 \mathrm{~cm}$ & $\begin{array}{l}\text { Depending on the fre- } \\
\text { quency } 1-5 \mathrm{~mm}\end{array}$ \\
\hline Depth of stimulation & Unlimited & Undetectable & $\begin{array}{l}\sim 1-1.5 \mathrm{~cm} \text { unless } \mathrm{H} \text {-coil } \\
\text { is used }\end{array}$ & $10-15 \mathrm{~cm}$ or more \\
\hline $\begin{array}{c}\text { Duration of reversible } \\
\text { effect }\end{array}$ & $\sim 5 \mathrm{~s}$ & $24 \mathrm{~h}$ & $\sim 5 s$ & 10-40 min \\
\hline fMRI brain mapping & Difficult & Difficult & Very difficult & Easily possible \\
\hline
\end{tabular}

prominent role in brain stimulation and brain mapping in the future (Bystritsky et al., 2011).

Targeting desired ROIs in the brain for stimulation with high spatial resolution is one of applicable features of LIFU, which could be done under the guidance of real time brain imaging (Figure 1). Furthermore, LIFU could be applied on several ROIs in the brain simultaneously or separately even if they are inhibitory or excitatory. Another important feature is its non-invasiveness (transcranial). In other words, ROIs can be controlled by phase shifting the instrument without any mechanical movement or any operation (Clement \& Hynynen, 2002; Hynynen et al., 2004; Tyler, 2011). LIFU stimulation has been tested on animal models and it is going to be used on human subjects in the same way as therapeutic HIFU (Bystritsky et al., 2011).

\subsection{Can LIFU stimulation change brain function?}

In 2008, Tyler and his colleagues discovered that LIFU can stimulate membrane ion channels and synaptic transmissions (Tyler et al., 2008). They also proposed a novel protocol for using LIFU brain stimulation for both activating mice's motor cortex and inhibiting spike activity in pentylenetetrazol-induced epileptic seizures (Tufail et al., 2010; Tufail, Yoshihiro, Pati, Li, \& Tyler, 2011; Tufail, 2011). Later, via functional magnetic resonance imaging (fMRI), Yoo and colleagues illustrated that LIFU can not

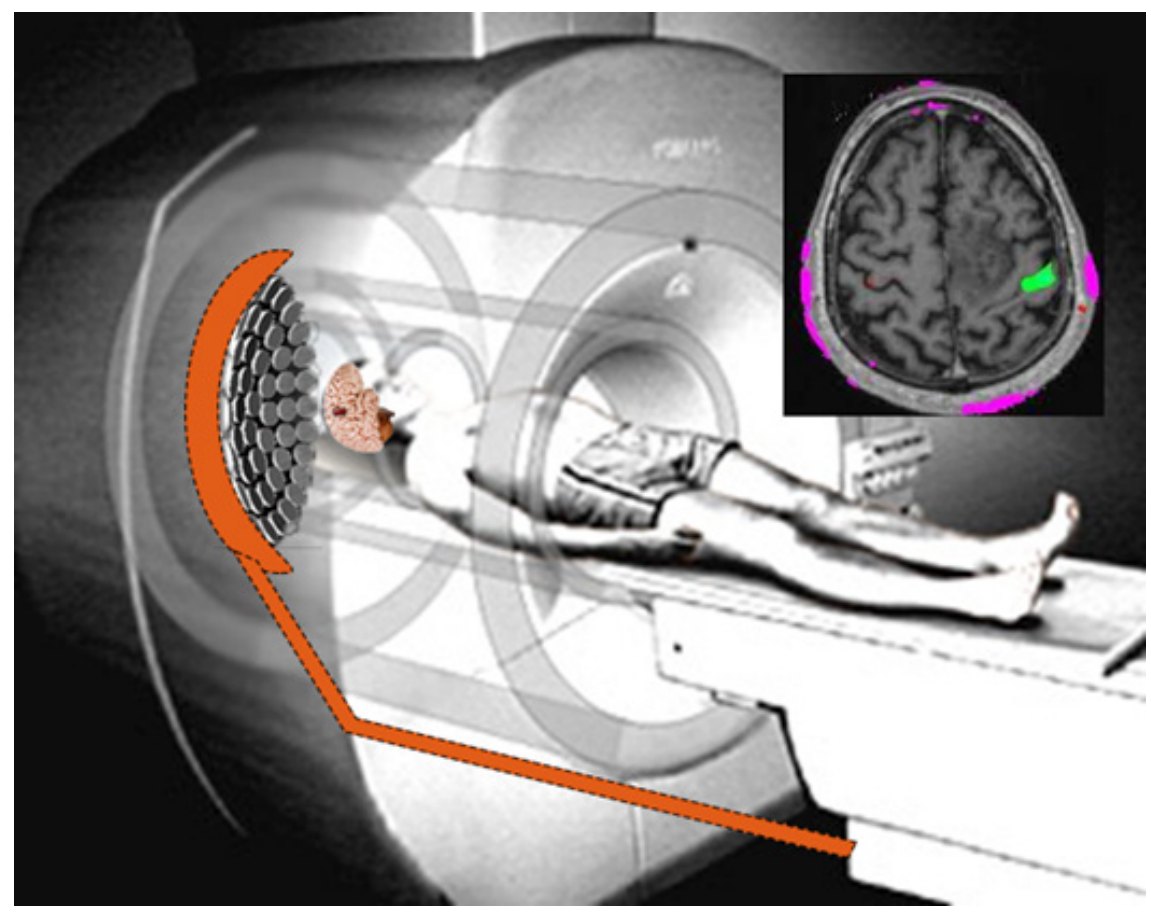

NEUR:SCIENCE

Figure 1. The proposed system is used simultaneously within fMRI imaging. Array transducers put focal point on region of interest (array transducer are adopted from Okita, Ono, Takagi, \& Matsumoto, 2010). 
only excite or inhibit particular activities in the cortex, but also cause visible changes in blood oxygenation leveldependent signal (Yoo et al., 2011).

Adequate research on the effectiveness of LIFU has been done already. To sum up, neuromodulatory properties of LIFU stimulation has been represented by electrophysiological recordings (Bystritsky et al., 2011), direct motion detection, fMRI imaging, confocal imaging (Tyler et al., 2008), microdialysis sampling of neurotransmitters (Min et al., 2011; Tyler et al., 2008), and positron emission tomography imaging (Kim et al., 2013). Based on the presented evidence, the neural activity modulation effect of LIFU is proved. Now the question is the mechanism behind it.

2.3. How does LIFU stimulation modulate neuronal functions?

The major effects of ultrasound wave on tissues (based on parameters; intensity, frequency, and period of stimulation) can be divided into thermal and nonthermal ones. The effects of LIFU stimulation are in nonthermal division. But, the dominant effects of ultrasound in high intensities lie in the thermal part (Tsui, Wang, \& Huang, 2005). Although, heating can increase excitability of neurons, in very high intensities, it can decrease synaptic transmission, tissue homogenization, protein denaturation, and DNA fragmentation. These parameters may either cause suppression or activation of neuronal activities (Coakley \& Dunn, 2005; Lin, Chen, Lu, Liu, \& Yang, 2015).

Nonthermal effects are categorized into mechanical and cavitation effects. The latter refers to the gas bubbles formed as a result of shockwave fluctuations (O'Brien, 2007; ter Haar, 2007). The effect of cavitation depends on the pressure, frequency of mechanical waves, and the existence of gas in the medium (Rezayat, 2011; Rezayat, Zahedi, \& Tavakkoli, 2011). Major histological analyses confirm that LIFU stimulation has no side effects on surrounding tissues of the ROIs (Bystritsky et al., 2011; Jolesz \& Hynynen, 2013). In other words, cavitation does not occur in LIFU stimulation.

Other major effects of ultrasound waves is acoustic radiation forces produced as a result of the momentum travelling from the acoustic field to the medium (Dalecki, 2004; O'Brien, 2007). These radiation forces are responsible for the production of radiation torque and acoustic streaming, and are also capable of displacing small ions, molecules, and organelles or inducing movement of the fluid along and around cell membranes (Johns, 2002). Tyler and colleagues believed that low intensity ultrasound may modulate neuronal excitability in 2 ways: 1) mechanical stress might change the viscoelastic properties of lipid bilayers and 2) mechano- sensitive transmembrane proteins may modulate receptor channel gating kinetics (Johns, 2002; Morris \& Juranka, 2007; Tyler, Tufail, \& Pati, 2010). Recent observations have indicated that LIFU could activate voltage-gated sodium and calcium channels, thereby eliciting action potentials and synaptic transmission. In fact, these results ratify Tyler 's second hypothesis (Bachtold, Rinaldi, Jones, Reines, \& Price, 1998; Boland \& Drzewiecki, 2008; Morris \& Juranka, 2007; Rinaldi, Jones, Reines, \& Price, 1991; Sachs, 2010; Sukharev \& Corey, 2004; Tyler et al., 2008).

Similarly, a model has been proposed which incorporates the effect of acoustic radiation force on cells as a result of changes in membrane capacitance (Plaksin, Shoham, \& Kimmel, 2014). On the other hand, radiation forces play a crucial role in endothelial nitric oxide synthesis, which in turn regulates the functions of ion channels. This might open another discussion on the mechanism of LIFU (Altland, Dalecki, Suchkova, \& Francis, 2004; Iida et al., 2006; Sugita et al., 2008). Nonetheless, this matter has remained unknown and several hypotheses are under investigation at cellular, molecular, and theoretical level.

Various research have been performed to find out appropriate parameter for LIFU brain stimulation in order to figure out its underlying mechanism (King, Brown, Newsome, \& Pauly, 2013; King, Brown, \& Pauly, 2014; Mehić et al., 2014; Yoo et al., 2010). King repeated precisely Tyler's protocol and showed that the probability of motor response increases as a function of acoustic intensity, acoustic duration, and their interaction. Furthermore, continuous-wave stimuli are as effective as pulsed stimuli in eliciting responses (King et al., 2013). Pursuing this line of research can help in shedding out the mystery of LIFU mechanism.

2.4. Can LIFU stimulation change corticospinal, thalamocortical, and corticocortical pathways?

LIFU brain stimulation has been recruited in some brain pathways (Table 3), based on their respective brain stimulation pathways. First in corticospinal pathway, Tufail and Tyler applied LIFU stimulation on primary motor cortex (based on cortical map) and observed direct movement in corresponding body parts; for example, movements were evoked in mice's paws, whiskers, and tails (Tufail et al., 2010). They found that the success of brain activation with LIFU stimulation depends highly on the plane of anesthesia which was evident in other studies (Kim et al., 2012; King, Brown, Newsome, \& Pauly, 2013; Yoo, Kim, Filandrianos, Taghados, \& Park, 2013). Moreover, Mehic and colleagues followed the same research approach using higher frequencies (2-MHz carrier signal dynamically with a 500- 
Table 3. Summary of LIFU stimulation studies categorized based on brain pathways.

\begin{tabular}{|c|c|c|c|}
\hline \multicolumn{2}{|r|}{ Region } & Result & Author/Year \\
\hline \multirow{6}{*}{ 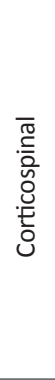 } & Mice motor cortex & $\begin{array}{l}\text { LIFU increases cortical spikes in motor cortex and produces muscle contrac- } \\
\text { tion selectively. }\end{array}$ & Tufail et al., 2010 \\
\hline & Rabbits motor cortex & LIFU activates motor cortex and produces muscle contraction selectively. & Yoo, et al., 2011 \\
\hline & Rat motor cortex & $\begin{array}{l}\text { LIFU activates motor cortex in order to connect brain-to-brain between hu- } \\
\text { man and mice. }\end{array}$ & Yoo et al., 2013 \\
\hline & Mice motor cortex & $\begin{array}{l}\text { Investigating LIFU parameters in motor activation: continuous/pulse, acoustic } \\
\text { intensities, acoustic durations and time intervals }\end{array}$ & King et al., 2013 \\
\hline & Rat motor cortex & Improving spatial resolution of LIFU stimulation on motor cortex ( $3 \mathrm{~mm}$ ) & King et al., 2014 \\
\hline & Rat motor cortex & Using LIFU, it provides map of rat motor cortex with $1 \mathrm{~mm}$ spatial resolution. & Mehic et al., 2014 \\
\hline \multirow{4}{*}{ 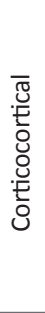 } & Rabbits visual cortex & $\begin{array}{l}\text { Primary visual cortex was inhibited and the magnitudes of p30 component in } \\
\text { visual evoked potential have been reduced } 11 \text { minutes after LIFU stimulation. }\end{array}$ & Yoo et al., 2011 \\
\hline & $\begin{array}{l}\text { Human primary somatosen- } \\
\text { sory cortex }\end{array}$ & $\begin{array}{l}\text { LIFU stimulation modulated the spectral content of sensory-evoked brain os- } \\
\text { cillations. LIFU stimulation targeted to } \mathrm{S} 1 \text { enhanced performance on sensory } \\
\text { discrimination tasks without affecting task attention or response bias. }\end{array}$ & Legon et al., 2014 \\
\hline & $\begin{array}{l}\text { Human posterior frontal } \\
\text { cortex }\end{array}$ & $\begin{array}{l}\text { Subjective reports of mood/global affect were improved } 10 \mathrm{~min} \text { and } 40 \mathrm{~min} \\
\text { following LIFU compared with placebo. }\end{array}$ & Hameroff et al., 2012 \\
\hline & Monkey left frontal eye field & LIFU stimulation modulated latencies in anti-saccade task. & Deffieux et al., 2013 \\
\hline \multirow{3}{*}{ 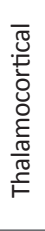 } & Rats thalamus & $\begin{array}{l}\text { LIFU stimulation in thalamus increased extracellular levels of serotonin and } \\
\text { dopamine for } 120 \text { min in frontal lobe }\end{array}$ & Min et al., 2011 \\
\hline & Rats thalamus & $\begin{array}{l}\text { LIFU spatially distinct increases in the glucose metabolic activity (PET imaging) } \\
\text { in the rat brain are present only at the center of sonication focus. }\end{array}$ & Kim et al., 2013 \\
\hline & Rats thalamus & $\begin{array}{l}\text { The LIFU stimulation in thalamus reduced the time took the animals got } \\
\text { anesthetized. }\end{array}$ & Yoo et al., 2011 \\
\hline \multirow{5}{*}{ 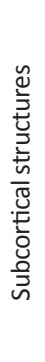 } & $\begin{array}{l}\text { Mice hippocampal slice } \\
\text { cultures }\left(\mathrm{CA}_{1}\right)\end{array}$ & $\begin{array}{l}\text { LIFU stimulation activates voltage-gated sodium channels, voltage-dependent } \\
\text { calcium transients, synaptic vesicle exocytosis, and synaptic transmission }\end{array}$ & Tyler et al., 2008 \\
\hline & Mice hippocampus & $\begin{array}{l}\text { LIFU stimulation inhibits triggered local field potential in } \mathrm{CA}_{1} \text { and increased } \\
\text { spike frequency }\end{array}$ & Tufail et al., 2010 \\
\hline & Rats hippocampus & $\begin{array}{l}\text { The occurrence of epileptic EEG bursts from epilepsy-induced rats decreased } \\
\text { after LIFU stimulation compared to the presonication epileptic state. }\end{array}$ & Min et al., 2011 \\
\hline & Rats hippocampus & $\begin{array}{l}\text { LIFU stimulations have neuroprotective effects against cerebral damages and } \\
\text { causes memory retention in Alzheimer disease }\end{array}$ & Lin et al., 2015 \\
\hline & Rat abducens nerve & LIFU stimulates the rat abducens nerve and make eyeball movement. & Kim et al., 2012 \\
\hline
\end{tabular}

NEUR:SCIENCE

$\mathrm{kHz}$ signal) which increased the anatomical resolution of neuromodulation about $1 \mathrm{~mm}$ (Mehić et al., 2014).

Min delivered focused ultrasound to the thalamic areas in order to modulate the extracellular level of dopamine and serotonin in thalamocortical pathway. It altered the extracellular concentration of these monoamine neurotransmitters which in turn had a potential modulatory effect on their local release, uptake, or degradation (Min et al., 2011). Furthermore, Yoo reported that the application of LIFU to the thalamus of anesthetized rats reduced the recovery time of voluntary movements due to intraperitoneal ketamine-xylazine anesthesia (Yoo, Kim, Min, \& Franck, 2011).

In another study, the same group, using acute epilepsy model in animal, found that LIFU suppressed the number of epileptic signal bursts (Min et al., 2011). The modulatory effects of LIFU on anesthesia suggests potential therapeutic applications for consciousness disorders such as minimally consciousness states (Yoo, et al., 2011).

By LIFU stimulation in hippocampus area, Tufial and associates stimulated neuronal activity in order to synchronize oscillations in the intact hippocampus (Tufail et al., 2011). Recently, Lin and colleagues, by stimulating the same area, indicated that LIFU not only has neuroprotective effects against cerebral damages, but also causes memory retention in Alzheimer disease (Lin et al., 2015).

In nonhuman primates there is one study in which the ability of LIFU stimulation on prefrontal areas of 2 macaque rhesus monkeys was explored (Deffieux et al., 2013). The results showed that ultrasound significantly modulated antisaccade (AS) task latencies as a sample of high-level cognitive behavior (Deffieux et al., 2013). Since using LIFU in human brain by Hameroff and colleagues for the first time 
(Hameroff et al., 2013), several studies were done on human subjects. Hameroff targeted scalp over posterior frontal cortex, contralateral to maximal pain, for 15 seconds in a doubleblind crossover study. They found improvement in subjective mood 10 minutes and 40 minutes after ultrasound stimulation (Hameroff et al., 2013). Another study, on human subjects, probed the influence of LIFU on the primary somatosensory cortex (Legon et al., 2014).

The stimulation volume size was $4.9 \mathrm{~mm}$ in depth and 18 $\mathrm{mm}$ in diameter which could significantly attenuate the amplitudes of somatosensory evoked potentials from median nerve stimulation (Legon et al., 2014). Similarly, suppression in p30 component of visual evoked potential by LIFU stimulation was indicated. Therefore, LIFU stimulation provides new insight in corticocortical pathways. However, more investigations are needed to better understand brain pathways. Also, LIFU can stimulate several ROIs in brain and this ability provides access to several pathways simultaneously.

\subsection{When will LIFU's safety be approved for clinical} human brain stimulation?

Most studies reported no sign of heat or cavitation by histological examination both within RIOs or surrounding tissues. Acoustic parameters of ultrasound waves used in LIFU stimulation are below the standard level defined for medical use in mechanical index (MI), thermal index for soft tissue (TIs), and thermal index for cranial bone (TIc). For instance, Hameroff used LIFU with acoustic output values of $\mathrm{MI}=0.7$, $\mathrm{TI}=0.5$, and $\mathrm{TIc}=0.2$ (below $\mathrm{FDA}$ guidelines of maximum MI of 1.9 and TI of 6.0) (Hameroff et al., 2013). Legon pointed out that the changes induced by LIFU are reversible and the performance on sensory discrimination tasks can be enhanced without affecting the attention task or response biases (Legon et al., 2014). It is therefore predicted that in near future we may see this technique in clinics as more patents are now granted on it.

\section{Discussion}

One of the thought-provoking and needed techniques in brain stimulation is the selection of special small 3D ROIs in the brain to transcranially stimulate it without damaging other tissues. As discussed above, LIFU brain stimulation, which is an accessible solution, can both activate and inhibit neural cells noninvasively. Identification of LIFU parameters for neuromodulation is essential for exploring its unknown mechanisms. There may be unknown ion channels or structures in neuron membranes that respond to acoustic field with corresponding changes. Also, there may be some receptors which release substances like neurotrophin growth factors or neurotransmitters. Using the LIFU stimulation in other brain pathways with high spatial resolution provides the possibility of precisely modulating corticothalamic, corticocortical, and thalamocortical pathways. This finding can be used for brain mapping or treatment of neurologic disorders such as chronic pain, obesity, Parkinson disease, epilepsy, obsessive compulsive disorder, and mental or movement disorders

In order to consider the safety issues, such studies are needed to be conducted on primate brains such as monkeys who have a skull with similar thickness and size to that of humans Future studies should put emphasis on testing 3D stimulation of brain ROI's by means of LIFU in phantom and human skull.

\section{Acknowledgments}

We should thank Dr. Hamidreza Pouretemad for his guidance and support in the current research.

\section{References}

Altland, O., Dalecki, D., Suchkova, V., \& Francis, C. (2004). Low-intensity ultrasound increases endothelial cell nitric oxide synthase activity and nitric oxide synthesis. Journal of Thrombosis and Haemostasis, 2(4), 637-643.

Bachtold, M. R., Rinaldi, P. C., Jones, J. P., Reines, F., \& Price, L. R. (1998). Focused ultrasound modifications of neural circuit activity in a mammalian brain. Ultrasound in Medicine \& Biology, 24(4), 557-565.

Bauer, R., Martin, E., Haegele-Link, S., Kaegi, G., von Specht, M., \& Werner, B. (2014). Noninvasive functional neurosurgery using transcranial MR imaging-guided focused ultrasound. Parkinsonism E Related Disorders, 20, 197-199.

Boland, L. M., \& Drzewiecki, M. M. (2008). Polyunsaturated fatty acid modulation of voltage-gated ion channels. Cell Biochemistry and Biophysics, 52(2), 59-84.

Bronstein, J. M., Tagliati, M., Alterman, R. L., Lozano, A. M., Volkmann, J., Stefani, A., et al. (2011). Deep brain stimulation for Parkinson disease: an expert consensus and review of key issues. $\mathrm{Ar}$ chives of Neurology, 68(2), 165-165.

Bystritsky, A., Korb, A. S., Douglas, P. K., Cohen, M. S., Melega, W P., Mulgaonkar, A. P., et al. (2011). A review of low-intensity focused ultrasound pulsation. Brain Stimulation, 4(3), 125-136.

Clement, G., \& Hynynen, K. (2002). A non-invasive method for focusing ultrasound through the human skull. Physics in Medicine and Biology, 47(8), 1219.

Coakley, W., \& Dunn, F. (2005). Degradation of DNA in High-Intensity Focused Ultrasonic Fields at $1 \mathrm{MHz}$. The Journal of the Acoustical Society of America, 50(6), 1539-1545.

Dalecki, D. (2004). Mechanical bioeffects of ultrasound. Annual Review of Biomedical Engineering, 6, 229-248. 
Deffieux, T., Younan, Y., Wattiez, N., Tanter, M., Pouget, P., \& Aubry, J. F. (2013). Low-intensity focused ultrasound modulates monkey visuomotor behavior. Current Biology, 23(23), 2430-2433.

Diester, I., Kaufman, M. T., Mogri, M., Pashaie, R., Goo, W., Yizhar, O., et al. (2011). An optogenetic toolbox designed for primates. $\mathrm{Na}$ ture Neuroscience, 14(3), 387-397.

Fenno, L. E., \& Deisseroth, K. (2014). Optogenetic Tools for Control of Neural Activity. Springer: Humana Press.

Hameroff, S., Trakas, M., Duffield, C., Annabi, E., Gerace, M. B., Boyle, P., et al. (2013). Transcranial ultrasound (TUS) effects on mental states: A pilot study. Brain Stimulation, 6(3), 409-415.

Hoskins, P. R., Martin, K., \& Thrush, A. (2010). Diagnostic ultrasound: physics and quipment. Cambridge: Cambridge University Press.

Hynynen, K., Clement, G. T., McDannold, N., Vykhodtseva, N., King, R., White, P. J., et al. (2004). 500-element ultrasound phased array system for noninvasive focal surgery of the brain: A preliminary rabbit study with ex vivo human skulls. Magnetic Resonance in Medicine, 52(1), 100-107.

Iida, K., Luo, H., Hagisawa, K., Akima, T., Shah, P. K., Naqvi, T. Z., et al. (2006). Noninvasive low-frequency ultrasound energy causes vasodilation in humans. Journal of the American College of Cardiology, 48(3), 532-537.

Johns, L. D. (2002). Nonthermal effects of therapeutic ultrasound: the frequency resonance hypothesis. Journal of Athletic Training, 37(3), 293.

Jolesz, F. A., \& Hynynen, K. H. (2013). MRI-guided focused ultrasound surgery. Boca Raton: CRC Press.

Kim, H., Park, M. A., Wang, S., Chiu, A., Fischer, K., \& Yoo, S. S. (2013). PET/CT imaging evidence of FUS-mediated (18) F-FDG uptake changes in rat brain. Medical Physics, 40(3), 033501.

Kim, H., Taghados, S. J., Fischer, K., Maeng, L. S., Park, S., \& Yoo, S. S. (2012). Noninvasive transcranial stimulation of rat abducens nerve by focused ultrasound. Ultrasound in Medicine $\mathcal{E}$ Biology, 38(9), 1568-1575.

King, R. L., Brown, J. R., Newsome, W. T., \& Pauly, K. B. (2013). Effective Parameters for Ultrasound-Induced In Vivo Neurostimulation. Ultrasound in Medicine E Biology, 39(2), 312-331.

King, R. L., Brown, J. R., \& Pauly, K. B. (2014). Localization of Ultrasound-Induced In Vivo Neurostimulation in the Mouse Model. Ultrasound in Medicine E Biology, 40(7), 1512-1522.

Legon, W., Sato, T. F., Opitz, A., Mueller, J., Barbour, A., Williams, A., et al. (2014). Transcranial focused ultrasound modulates the activity of primary somatosensory cortex in humans. Nature Neuroscience, $17(2)$, 322-329.

Lin, W. T., Chen, R. C., Lu, W. W., Liu, S. H., \& Yang, F. Y. (2015). Protective effects of low-intensity pulsed ultrasound on aluminuminduced cerebral damage in Alzheimer's disease rat model. Scientific Reports, 5, 9671. doi: 10.1038/srep09671.

Lipsman, N., Schwartz, M. L., Huang, Y., Lee, L., Sankar, T., Chapman, M., et al. (2013). MR-guided focused ultrasound thalamotomy for essential tremor: A proof-of-concept study. Lancet Neurology, 12(5), 462-468.

Mehić, E., Xu, J. M., Caler, C. J., Coulson, N. K., Moritz, C. T., \& Mourad, P. D. (2014). Increased Anatomical Specificity of Neuro- modulation via Modulated Focused Ultrasound. PloS One, 9(2), e86939.

Min, B. K., Bystritsky, A., Jung, K. I., Fischer, K., Zhang, Y., Maeng, L. S., et al. (2011). Focused ultrasound-mediated suppression of chemically-induced acute epileptic EEG activity. BMC Neuroscience, 12(1), 23.

Min, B. K., Yang, P. S., Bohlke, M., Park, S., R Vago, D., Maher, T. J., et al. (2011). Focused ultrasound modulates the level of cortical neurotransmitters: Potential as a new functional brain mapping technique. International Journal of Imaging Systems and Technology, 21(2), 232-240.

Morris, C. E., \& Juranka, P. F. (2007). Nav channel mechanosensitivity: Activation and inactivation accelerate reversibly with stretch. Biophysical Journal, 93(3), 822-833.

Muggleton, N., \& Walsh, V. (2012). Smaller magnets for smarter minds? Trends in Cognitive Sciences, 16(9), 452-453.

O'Brien, W. D. (2007). Ultrasound-biophysics mechanisms. Progress in Biophysics and Molecular Biology, 93(1-3), 212-255.

Parasuraman, R., Christensen, J., \& Grafton, S. (2012). Neuroergonomics: The brain in action and at work. Neuroimage, 59(1), 1-3.

Peterchev, A. V., Wagner, T. A., Miranda, P. C., Nitsche, M. A., Paulus, W., Lisanby, S. H., et al. (2012). Fundamentals of transcranial electric and magnetic stimulation dose: Definition, selection, and reporting practices. Brain Stimulation, 5(4), 435-453.

Plaksin, M., Shoham, S., \& Kimmel, E. (2014). Intramembrane Cavitation as a Predictive Bio-Piezoelectric Mechanism for Ultrasonic Brain Stimulation. Physical Review X, 4(1), 011004

Rezayat, E. (2011). Ultrasound intensity exposimetry in physiotherapy devices using micro-bubbles (Doctoral dissertation). Tehran: Sharif University.

Rezayat, E., Zahedi, E., \& Tavakkoli, J. (2011). Ultrasound dosimetery using microbubbles. Paper presented at the Asian Pacific Conference on Medical and Biological Engineering, Kuala Lumpur, Malaysia, 20-23 June 2011.

Rinaldi, P. C., Jones, J. P., Reines, F., \& Price, L. R. (1991). Modification by focused ultrasound pulses of electrically evoked responses from an in vitro hippocampal preparation. Brain Research, 558(1), $36-42$

Sachs, F. (2010). Stretch-activated ion channels: what are they? Physiology, 25(1), 50-56.

Sugita, Y., Mizuno, S., Nakayama, N., Iwaki, T., Murakami, E., Wang, Z., et al. (2008). Nitric oxide generation directly responds to ultrasound exposure. Ultrasound in Medicine E Biology, 34(3), 487-493.

Sukharev, S., \& Corey, D. P. (2004). Mechanosensitive channels: multiplicity of families and gating paradigms. Science Signaling, 2004(219), re4

ter Haar, G. (2007). Therapeutic applications of ultrasound. Progress in Biophysics and Molecular Biology, 93(1), 111-129.

Tsui, P. H., Wang, S. H., \& Huang, C. C. (2005). In vitro effects of ultrasound with different energies on the conduction properties of neural tissue. Ultrasonics, 43(7), 560-565. 
Tufail, Y., Matyushov, A., Baldwin, N., Tauchmann, M. L., Georges, J., Yoshihiro, A., et al. (2010). Transcranial pulsed ultrasound stimulates intact brain circuits. Neuron, 66(5), 681-694.

Tufail, Y., Yoshihiro, A., Pati, S., Li, M. M., \& Tyler, W. J. (2011). Ultrasonic neuromodulation by brain stimulation with transcranial ultrasound. Nature Protocols, 6(9), 1453-1470.

Tufail, Y. Z. (2011). Development of a Neurostimulation Method Using Pulsed Ultrasound (Doctoral dissertaion). Tempe, Arizona: Arizona State University.

Tyler, W. J. (2011). Noninvasive neuromodulation with ultrasound? A continuum mechanics hypothesis. Neuroscientist, 17(1), 25-36.

Tyler, W. J., Tufail, Y., Finsterwald, M., Tauchmann, M. L., Olson, E. J., \& Majestic, C. (2008). Remote excitation of neuronal circuits using low-intensity, low-frequency ultrasound. PLoS One, 3(10), e3511.

Tyler, W. J., Tufail, Y., \& Pati, S. (2010). Pain: Noninvasive functional neurosurgery using ultrasound. Nature Reviews Neurology, 6(1), 13-14.

Ulmer, S., \& Jansen, O. (2013). Combining transcranial magnetic stimulation with (f) MRI. In G. Hartwigsen, T. Kassuba \& H. R. Siebner (Eds.), fMRI (pp. 283-297). Berlin: Springer Heidelberg.

Yoo, S. S., Bystritsky, A., Lee, J. H., Zhang, Y., Fischer, K., Min, B. K., et al. (2011). Focused ultrasound modulates region-specific brain activity. Neuroimage, 56(3), 1267-1275.

Yoo, S. S., Kim, H., Filandrianos, E., Taghados, S. J., \& Park, S. (2013). Non-invasive brain-to-brain interface (BBI): Establishing functional links between two brains. PloS One, 8(4), e60410.

Yoo, S. S., Kim, H., Min, B. K., \& Franck, S. P. E. (2011). Transcranial focused ultrasound to the thalamus alters anesthesia time in rats. Neuroreport, 22(15), 783.

Yoo, S. S., Jung, K., Zhang, Y., McDannold, N., Bystritsky, A., \& Jolesz, F. (2010). Non-invasive suppression of animal-model chronic epilepsy using image-guided focused ultrasound. Proceeding of the International Society for Magnetic Resonance in Medicine, 18, 105-111.

Zrinzo, L., Yoshida, F., Hariz, M. I., Thornton, J., Foltynie, T., Yousry, T. A., et al. (2011). Clinical safety of brain magnetic resonance imaging with implanted deep brain stimulation hardware: large case series and review of the literature. World Neurosurgery, 76(1), $164-172$ 